\title{
Paper
}

\section{Electrical Characteristics of Wireless Power Transfer System with Repeating Coil for AGV Considering the Misalignment of Coils}

\author{
AKIHIRo IMAKIIRE* ${ }^{* \dagger}$ Member, \\ Hideaki TOKUnaga ${ }^{\dagger}$ \\ AKIHIRO KAWAGOE ${ }^{\dagger}$ Non-member, \\ MASAYUKI HiKITA ${ }^{\dagger}$ \\ Non-member \\ Non-member
}

(Received May 10, 2018, revised September 18, 2018)

\begin{abstract}
This paper compares the electrical characteristics of S-P (Series - Parallel) type with those of a repeating coil type wireless power transfer (WPT) system. The features of the two types of WPT systems are described for same output power using the same coil model. In general, the misalignment of power transmitting and receiving coils causes an output power to decrease using resonance capacitors with large operations current and voltage. From the viewpoint, a compensation method for the misalignment is investigated to reduce this burden of the resonance capacitor. Simulation is made on electrical characteristics such as output power and power transfer efficiency of a proposed WPT system applied to an automatic guided vehicle (AGV) based on an equipment circuit combining the results of an electromagnetic analysis. As a result, it is found that a repeating coil keeping the center position between the primary and secondary coils can suppress the burden of the resonance capacitor so as to improve the transmission power of WPT system.
\end{abstract}

Keywords: wireless power transfer, repeating coil, automatic guided vehicle, relay coil

\section{Introduction}

In recent years, wireless power transfer (WPT) system has been researched for various applications, such as electric vehicles (EV) and automatic guided vehicles. There are a number of circuit configurations with different electrical characteristics for the WPT system [1] [4]. Circuit configuration of the S-P type WPT system commonly used for EV applications has two resonance capacitors: one connected in series with a primary coil, and the other connected in parallel with a secondary coil. On the other hand, the WPT system with a repeating coil (repeating coil type) is well known for its robust performance in the coil position. It is crucial to investigate the electrical characteristics against misalignment of the coil position for transmitting power to the load with high efficiency. A lot of other researchers [1] [4] have been made on the electrical characteristics of other coil types such as S-P type and repeating coil type for WPT system. However, it is difficult to compare the electrical characteristics under the same conditions, because each type of WPT system has different circuit configurations and coil shapes. Thus, it is needed to determine conditions suitable for each type of WPT system to be reasonably compared. Moreover, an investigation is also needed on parameters in the electrical characteristics to reduce time to conduct a simulation.

This paper compares the electrical characteristics of the S-P type and the repeating type WPT system. Namely, the

\footnotetext{
* Corresponding Author: imakiire@ele.kyutech.ac.jp

$\dagger$ Kyushi Institute of Technology, 1-1, Sensui, Tobata, Fukuoka, Japan, $804-8550$
}

two types of WPT system are compared under the conditions with the same output power using same coil model. In general, the misalignment of power transmitting and receiving coils causes an output power to decrease using resonance capacitors with large operations current and voltage. From the viewpoint, a compensation method for the misalignment is investigated to reduce this burden of the resonance capacitor. Simulation is made on electrical characteristics such as output power and power transfer efficiency of a proposed WPT system applied to an automatic guided vehicle (AGV) based on an equipment circuit combining the results of an electromagnetic analysis.

One of the main purposes of this paper is to provide optimum design conditions in the WPT system. Yamamoto et al. [5] investigated the burden of the resonance capacitor in a WPT system, while, Kitazawa et al. [6] and Zaheer et al. [7] studied compensation method for a coil misalignment using control or coil shapes. In addition, the literature [8] [10] showed two types dynamic WPT system using parallel line feeder or relay coil(repeating coil), respectively. On the other hand, we have studied the WPT system using the repeating coil with controlling the coil position [11] [12]. In this paper, we investigate the electrical characteristics, compensation method, and the burden of the capacitor, when the repeating coil maintains its position at the center between the primary and secondary coils.

\section{Proposed Wireless power transfer system configu- ration for automatic guided vehicle}

2.1 Overall WPT system for AGV Fig. 1(a) and (b) show electrical circuit and coil models of WPT system for 


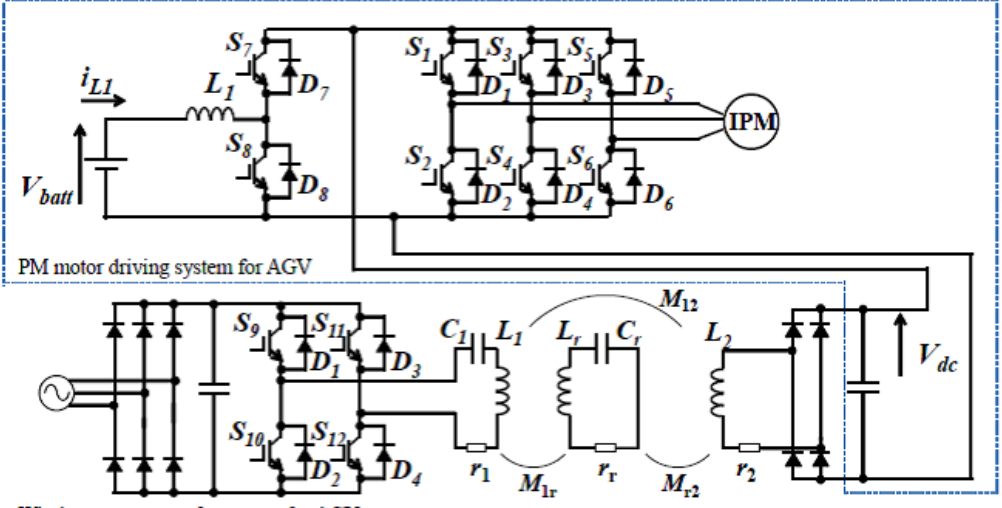

Wireless power transfer system for AGV
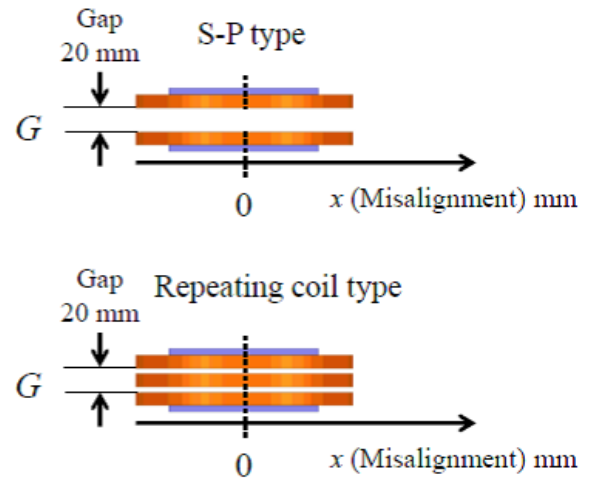

(a) System configuration

(b) Coils model, and motion of repeating and secondary coils

Figure 1: Wireless Power Transfer system with repeating coil for Automatic Guided Vehicle.

AGV investigated so far. As shown in Fig. 1(a), the circuit consists of a voltage booster to control the battery current, DC link capacitor used commonly in WPT system, and three-phase inverter for driving a motor of AGV. Fig. 1(b) shows the coil model and motions of repeating coil and secondary coils. Note that the secondary coil is located at an AGV. In contrast, the repeating coil is set at the center between the primary and secondary coils to keep the output voltage constant. In other words, movement of the repeating coil is controlled to suppress the decrease in the output power.

2.2 Simulation model of $S-P$ and the repeating coil types Fig. 2(a) and (b) show simulation models of the $\mathrm{S}-\mathrm{P}$ type and repeating coil type, respectively. Note that both types consist of same coil shape and the number of turns, while, the later type additionally includes the repeating coil set at the center of the primary and secondary coils. The gap length $G$ of $20 \mathrm{~mm}$ and misalignment are defined in Fig. 1 as parameter in the simulation.

Table 1 lists physical property values and size of the coil. In addition, the input voltage $V_{1}$ and the load resistance $R_{L}$ were set as sine waveforms and $100 \Omega$, respectively, in the simulation.

First, the output voltage and current of the power transmitting coil, receiving coil and repeating coil were simulated using electromagnetic analysis software (ANSYS, Maxwell and Simplorer), which also provided inductance and mutual inductance as the parameters as shown in Fig. 2.

Next, simulated results using the electromagnetic software and calculated ones using circuit equations were compared. As a result, the validity of calculation results using circuit equations was confirmed. Namely, calculated results derived using parameters such as the inductance $L$ and mutual inductance $M$ were simulated using the electromagnetic software. In general, circuit equations are useful to design an optimum WPT system when the influence of circuit parameters on the electrical characteristics of the WPT system is investigated.

Finally, the S-P type and repeating coil type calculation results were compared and discussed so as to investigate a

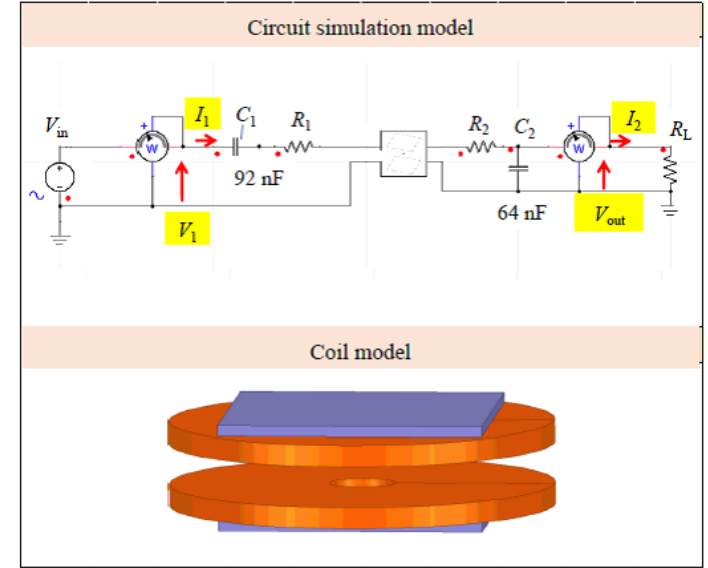

(a) S-P type

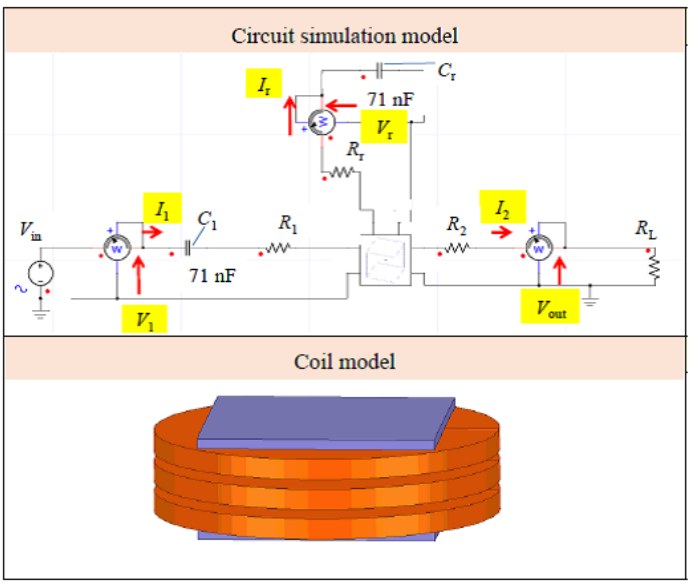

(b) Repeating coil type

Figure 2: Circuit and coil simulation models using electromagnetic analysis.

compensation method.

2.3 S-P type and the repeating coil type models Equations of the S-P type and the repeating coil type WPT system are expressed as equations (1) and (2), respectively. The capacitance of a resonance capacitor is set to adjust a power factor of the circuit at 1.0. Fig. 3 shows thus obtained 
Table 1: Simulation conditions.

\begin{tabular}{|c|c|}
\hline Parameters & Value \\
\hline Input voltage $V_{1}$ (S-P type) & $141 \mathrm{~V}_{\mathrm{rms}}$ \\
\hline Input voltage $V_{1}$ (Repeating coil type) & $141 V_{\text {rms }}$ \\
\hline $\begin{array}{l}\text { Input voltage } V_{1} \text { ' (Repeating coil type) } \\
\text { The output power is same value in the S-P type } \\
\text { and the repeating coil type }\end{array}$ & $254 V_{\text {rms }}$ \\
\hline Frequency of input voltage $V_{1}$ & $25 \mathrm{kHz}$ \\
\hline Gap length $G$ & $20 \mathrm{~mm}$ \\
\hline Misalignment $X$ & $0-80 \mathrm{~mm}$ \\
\hline Load resistance $R_{L}$ & $100 \Omega$ \\
\hline Inductance $L_{1}(\mathrm{~S}-\mathrm{P}$ type $) @$ No misalignment & $638 \mu \mathrm{H}$ \\
\hline Inductance $L_{2}(\mathrm{~S}-\mathrm{P}$ type $) @$ No misalignment & $637 \mu \mathrm{H}$ \\
\hline $\begin{array}{l}\text { Inductance } L_{1}(\text { Repeating coil type }) \\
@ \text { No misalignment }\end{array}$ & $573 \mu \mathrm{H}$ \\
\hline $\begin{array}{l}\text { Inductance } L_{r}(\text { Repeating coil type }) \\
\text { @ No misalignment }\end{array}$ & $638 \mu \mathrm{H}$ \\
\hline $\begin{array}{l}\text { Inductance } L_{2}(\text { Repeating coil type) } \\
\text { @ No misalignment }\end{array}$ & $638 \mu \mathrm{H}$ \\
\hline Resonance capacitor $C_{1}(\mathrm{~S}-\mathrm{P}$ type $)$ & $92 \mathrm{nF}$ \\
\hline Resonance capacitor $C_{2}(\mathrm{~S}-\mathrm{P}$ type $)$ & $64 \mathrm{nF}$ \\
\hline Resonance capacitor $C_{1}$ (Repeating coil type) & $71 \mathrm{nF}$ \\
\hline Resonance capacitor $C_{r}($ Repeating coil type $)$ & $71 \mathrm{nF}$ \\
\hline Internal resistance of coil $r_{1}, r_{r}, r_{2}$ & $0.173 \Omega$ \\
\hline Relative permeability of ferrite core & 2300 \\
\hline Ferrite core size & $125 \times 125 \times 5 \mathrm{~mm}$ \\
\hline Diameter of coil & $\Phi 175 \mathrm{~mm}$ \\
\hline Number of turns of coil & 75 \\
\hline
\end{tabular}

an equivalent circuit model of a repeating type WPT system. It can be seen that the equivalent circuit model of the repeating coil type is similar to that of the S-P type system. Furthermore, if the mutual inductances $M_{1 r}$ and $M_{r 2}$ have the same value, and the repeating resonance capacitor value is chosen as providing a resonance frequency with the repeating coil $L_{r}$, the output voltage can be constant. Fulfilling the above conditions allows us to eliminate the resonance capacitor $C_{2}$ in the circuit of the WPT system. If the repeating coil position is controlled at the center between the primary and secondary coils, the output voltage can be maintained at constant with the input voltage $V_{i n}$. Thus, the simulation on the electrical properties of the repeating coil type was made without the resonance capacitor $C_{2}$, as reported in the previous investigation [12] where the WPT system used not only repeating resonance capacitor but secondary resonance one. However, electrical characteristics of the S-P type and repeating coil type WPT system have not compared in detail under the condition that the repeating coil is controlled at the center of the primary and secondary coils intentionally.

$$
\begin{aligned}
& {\left[\begin{array}{c}
V_{1} \\
0
\end{array}\right]=\left[\begin{array}{cc}
r_{1}+j\left(\omega L_{1}-\frac{1}{\omega C_{1}}\right) & -j \omega M_{12} \\
j \omega M_{12} & -r_{2}-j\left(\omega L_{2}-\frac{\frac{R_{L}}{\omega C_{2}}}{R_{L}-j \frac{1}{\omega C_{2}}}\right)
\end{array}\right]\left[\begin{array}{c}
I_{1} \\
I_{2}
\end{array}\right]} \\
& {\left[\begin{array}{c}
V_{1} \\
0 \\
0
\end{array}\right]=\left[\begin{array}{ccc}
r_{1}+j\left(\omega L_{1}-\frac{1}{\omega C_{1}}\right) & -j \omega M_{1 r} & -j \omega M_{12} \\
j \omega M_{1 r} & -\left(r_{r}+j\left(\omega L_{r}-\frac{1}{\omega C_{r}}\right)\right. & -j \omega M_{r 2} \\
j \omega M_{12} & -j \omega M_{r 2} & -\left(r_{2}+j\left(\omega L_{2}-\frac{R_{L}}{\omega C_{2} R_{L}-j}\right)\right)
\end{array}\right]\left[\begin{array}{c}
I_{1} \\
I_{r} \\
I_{2}
\end{array}\right] \text { (2) }}
\end{aligned}
$$

Therefore, this paper dealt with each WPT system designed with the same output power using the same coil model, as well as, the burden of each resonance capacitor and change in the impedance locus observed according to the increase in the misalignment.

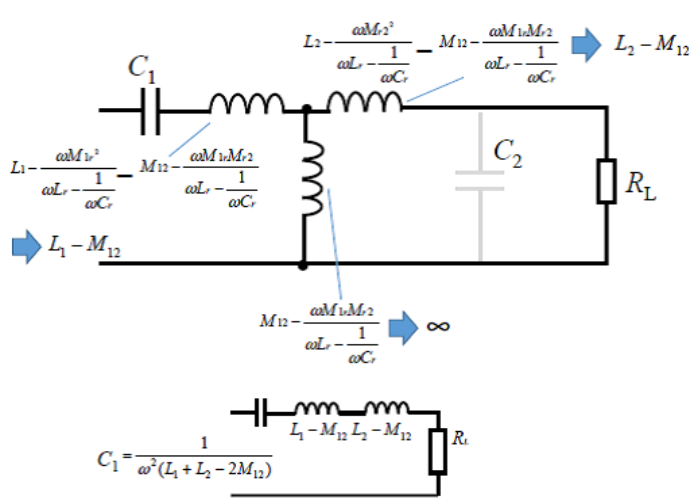

Figure 3: Equivalent circuit model of the repeating coil type WPT system.

Since the number of parameters influencing the electrical characteristics is large, the calculation was carried out using derived from the electromagnetic analysis. Note that output voltage of the S-P type WPT system larger than that of repeating coil type as expressed by equations (3) and (4), respectively.

$$
V_{\text {out_SP }}=\frac{L_{2}}{M_{12}} V_{1}
$$

$$
V_{\text {out_RC }}=V_{1}
$$

The simulation was performed with the same output power, meaning that the repeating coil type needs an inverter providing high voltage than the S-P type.

\section{Simulation results and discussion}

Fig. 4 and 5 show misalignment dependence of the output voltage and coil current characteristics of the S-P type and the repeating coil type WPT system obtained from the electromagnetic analysis and equations (1) and (2), respectively. As shown in the figures, results obtained from the electromagnetic analysis agree with those derived from the equations indicating a validity of the two different ways to the equations from the results of comparison between misalignment dependence of $V_{\text {out }}$. As well as other characteristics such as coil efficiency, output power, output voltage, and coil current and so on.

Note that the inductance $L$ and mutual inductance $M$ were calculated from the electromagnetic analysis.

Fig. 5(a) and (b) show the output voltage and coil current as a function of the misalignment for the S-P type and repeating coil type WPT system, respectively. Note in Fig. 6(a) that $V_{\text {in }}$ of the repeating coil type was set two times that of the S-P type to adjust the output power to that of the S-P type without misalignment.

Fig. 6(a) and (b) show the output power characteristics for misalignment. For this, the load was set at $100 \Omega$. In addition, in Fig. 6(a) and (b), the input voltage $V_{\text {in }}$ are different for the repeating coil type. In Fig. 6(a), the input voltage $V_{\text {in }}$ of the repeating coil type was set at the same value as that of the S-P type. In (b), the input voltage $V_{\text {in }}$ of the repeating coil type was set about two times that of the S-P type to 


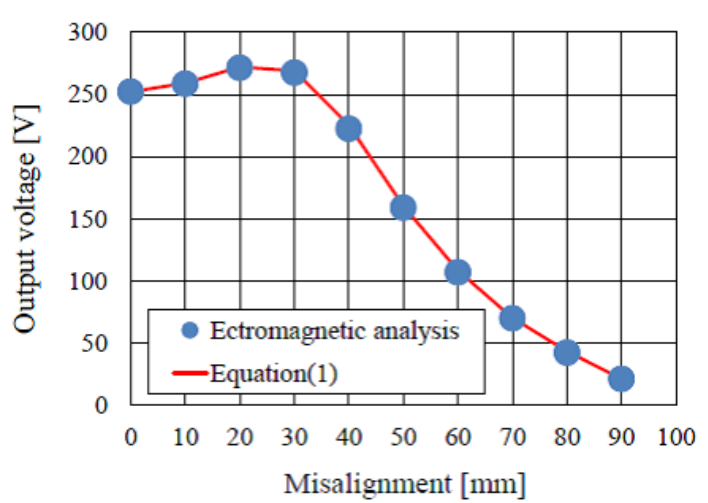

(a) Output voltage

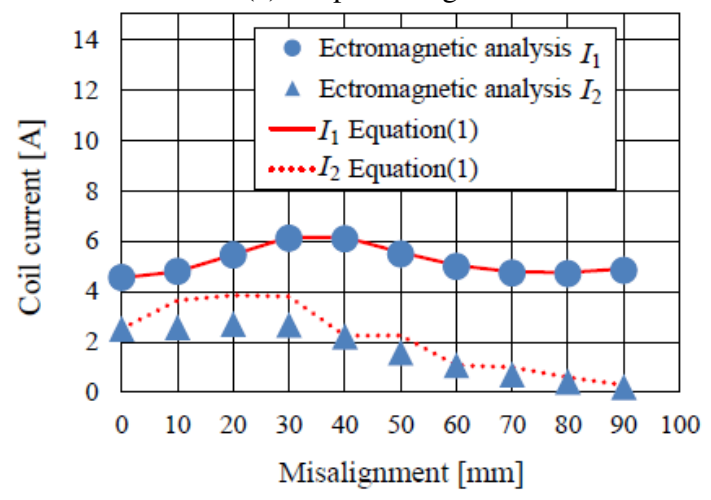

(b) Coil current

Figure 4: Simulation results of the S-P type.

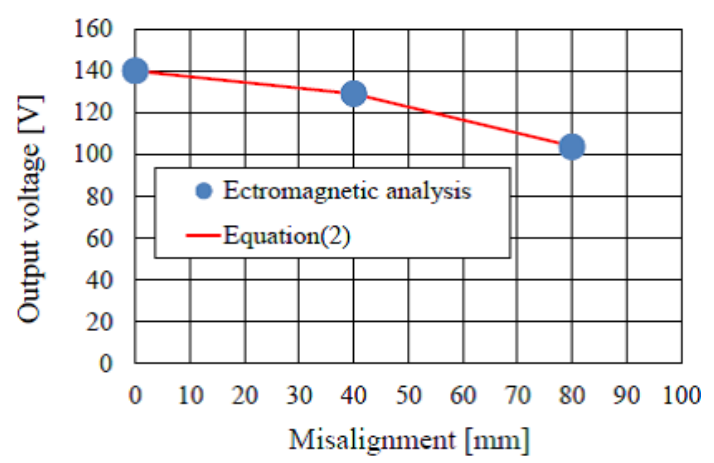

(a) Output voltage

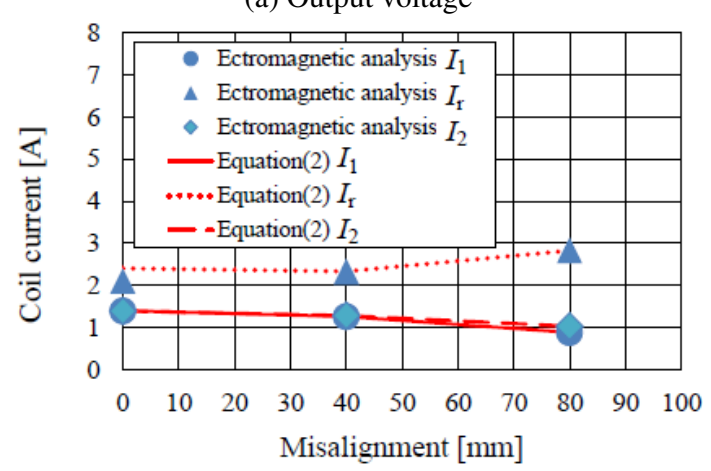

(b) Coil current

Figure 5: Simulation results of $\mathrm{WPT}_{\mathrm{RC}}$.

adjust the same output power of the S-P type under the no misalignment.

It is evident from Fig. 6(a) the repeating coil type WPT

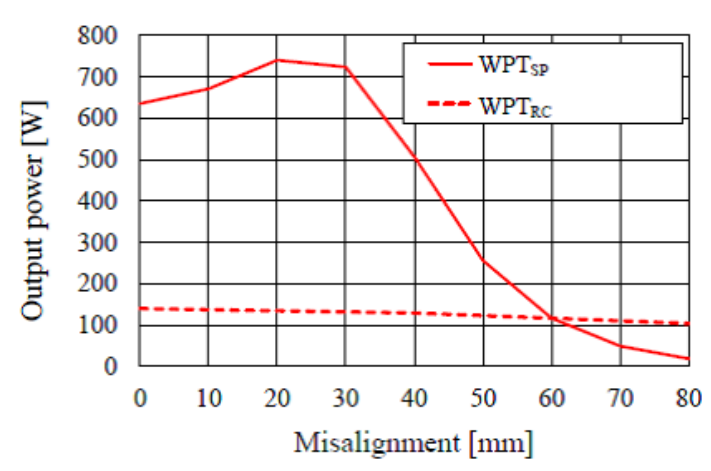

(a) Input voltage value is same the S-P type.

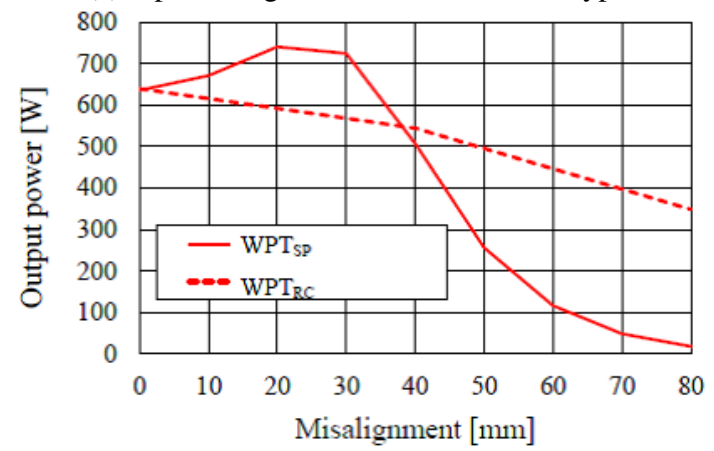

(b) Input voltage value of repeating coil type is two times of that of the S-P type

Figure 6: Output power as a function of coil misalignment of two types of WPT system.

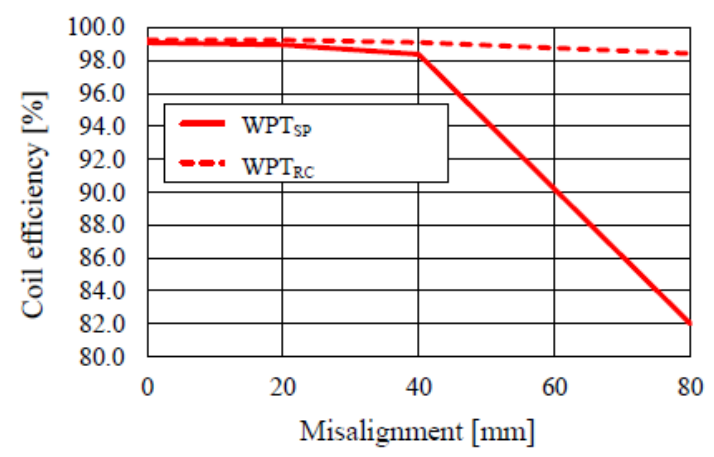

Figure 7: Coil efficiency as a function of misalignment of the two

system provides the lower output voltage and lower output power than the S-P type does. As a consequence $\mathrm{WPT}_{\mathrm{SP}}$ is superior to $\mathrm{WPT}_{\mathrm{RC}}$ for the same input voltage $V_{i n}$. On the other hand, as shown in Fig. 6(b), the output power of the $\mathrm{WPT}_{\mathrm{RC}}$ has the same value as $\mathrm{WPT}_{\mathrm{SP}}$, indicating $\mathrm{WPT}_{\mathrm{RC}}$ is superior to $\mathrm{WPT}_{\mathrm{SP}}$ in a low output power area. For example, $\mathrm{WPT}_{\mathrm{SP}}$ can provide $400 \mathrm{~W}$ of power transmission for about $40 \mathrm{~mm}$ of misalignment, while $\mathrm{WPT}_{\mathrm{RC}}$ can transmit the same power even for $80 \mathrm{~mm}$ in misalignment.

Next, an attempt was made to compare the coil efficiency defined as the only copper loss of a coil for the two types of WPT system.

Fig. 7 shows the coil misalignment dependence of the coil efficiency of the two types of WPT system. It is obvious the figure that $\mathrm{WPT}_{\mathrm{RC}}$ provides larger efficiency than $\mathrm{WPT}_{\mathrm{SP}}$, 


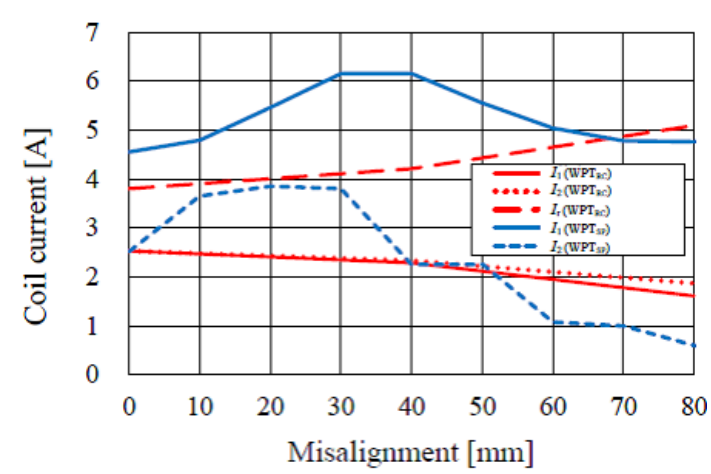

(a) Resonance capacitor current

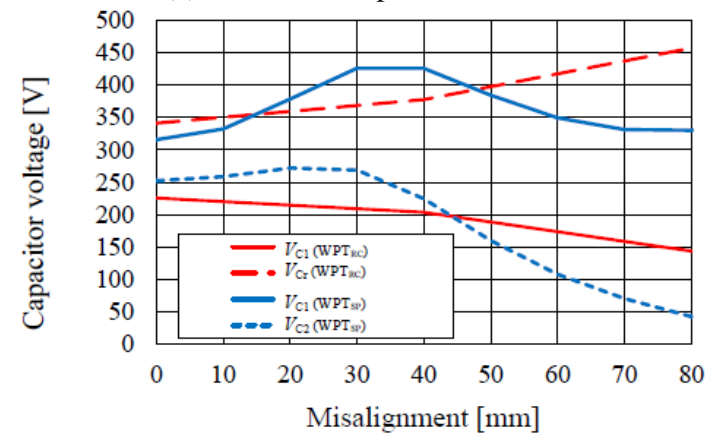

(b) Resonance capacitor voltage

Figure 8: Resonance capacitor's burden for misalignment of the two types of WPT system.

especially for larger misalignment. This result can be explained by a rapid decrease in the output power of $\mathrm{WPT}_{\mathrm{SP}}$ resulting in an increase in a reactive power. On the other hand, $\mathrm{WPT}_{\mathrm{RC}}$ maintains high coil efficiency even for low output power.

Fig. 8(a) and (b) show coil misalignment dependence of coil current and resonance capacitor voltage for the two types of WPT system. Note that input voltage $V_{\text {in }}$ of $\mathrm{WPT}_{\mathrm{RC}}$ was set two times that of $\mathrm{WPT}_{\mathrm{SP}}$. As shown the Fig. 8(b), the primary resonance capacitor has a larger burden than the secondary resonance capacitor in $\mathrm{WPT}_{\mathrm{SP}}$. In addition, the repeating resonance capacitor in $\mathrm{WPT}_{\mathrm{RC}}$ provides a larger burden than the primary resonance capacitor. The result indicates that the repeating resonance capacitor's burden should be considered in designing.

Next, we compared the impedance locus for misalignment of the two types of WPT system. Fig. 9 shows impedance viewed from the primary side. Circles and triangles in the figure indicate the impedances of $\mathrm{WPT}_{\mathrm{SP}}$ and $\mathrm{WPT}_{\mathrm{RC}}$, respectively. The result explains a robustness of $\mathrm{WPT}_{\mathrm{RC}}$. Namely, even if a large misalignment occurs, then leakage inductance increases, leading to an increase in the reactive power. As shown in Fig. 9, WPT $_{\text {SP }}$ provides the almost inductive load at $80 \mathrm{~mm}$ of the misalignment, while $\mathrm{WPT}_{\mathrm{RC}}$ does not the completely inductive load for the same misalignment. $\mathrm{WPT}_{\mathrm{RC}}$ has different impedance locus from $\mathrm{WPT}_{\mathrm{SP}}$.

The equivalent circuit of $\mathrm{WPT}_{\mathrm{RC}}$ as shown in Fig. 3 allows us to confirm a constant output voltage $V_{\text {out }}$ for same $M_{1 r}$ and $M_{r 2}$ and a repeating resonance capacitance with

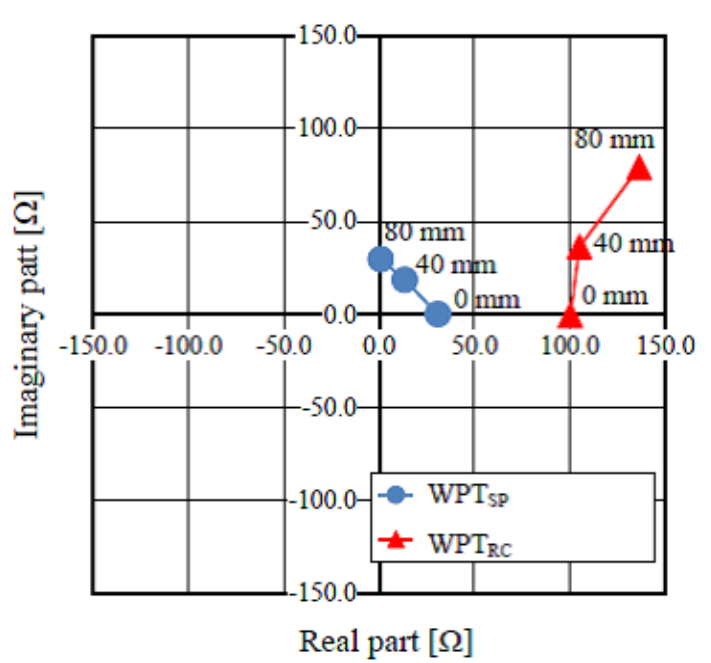

Figure 9: Impedance locus for misalignment of the two types.

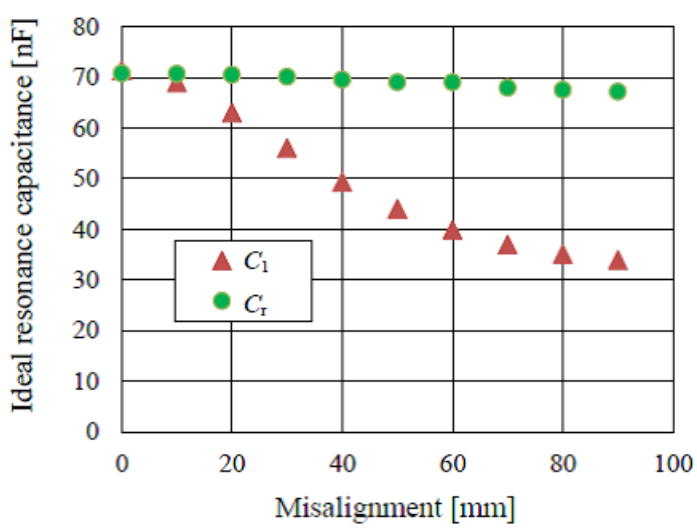

Figure 10: Ideal resonance capacitance as a function of the misalignment of $\mathrm{WPT}_{\mathrm{RC}}$.

a repeating coil $L_{r}$ to provide a resonance. Note, however, that the output power (output voltage) gently decreases with increasing misalignment, as shown in Fig. 6.

Fig. 10 shows ideal resonance capacitance $C_{1}$ and $C_{r}$ as a function of the misalignment of $\mathrm{WPT}_{\mathrm{RC}}$. As can be seen in the figure, both $C_{1}$ and $C_{r}$ decrease with an increase in misalignment, resulting in the decrease in output voltage with deviating from a designed value. Thus, additional control will be needed to maintain $V_{\text {out }}$ as a constant.

\section{Compensation method of misalignment and burden for resonance capacitor}

In this section, an investigation is made on a compensation method of the misalignment and burden for the resonance capacitor. Note that $\mathrm{WPT}_{\mathrm{RC}}$ can ignore $C_{2}$ irrespective of the misalignment.

Fig. 11 shows output voltage as a function of misalignment of $\mathrm{WPT}_{\mathrm{RC}}$ with the secondary resonance capacitor $C_{2}$ added. Note that $C_{2}$ was set at the value of $10 \%$ and $100 \%$ $C_{r}$. As can be seen in the figure, $V_{\text {out }}$ increases with increase of $C_{2}$, and then the output power increases with increasing in the misalignment. Obtained output voltage charac- 


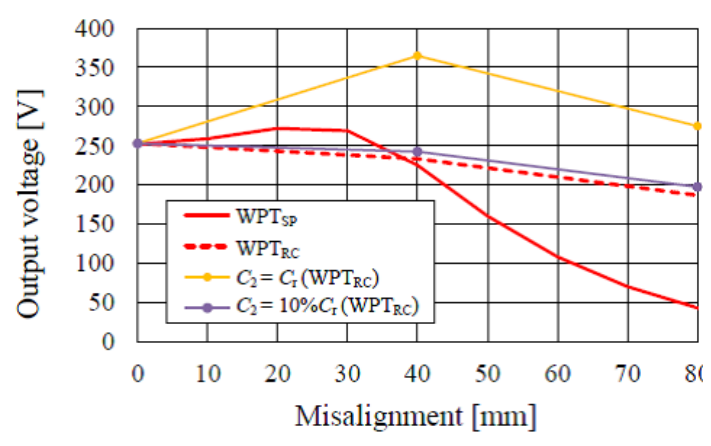

Figure 11: Output voltage as a function of the misalignment of the two types of WPT system with the resonance capacitor $C_{2}$ added.

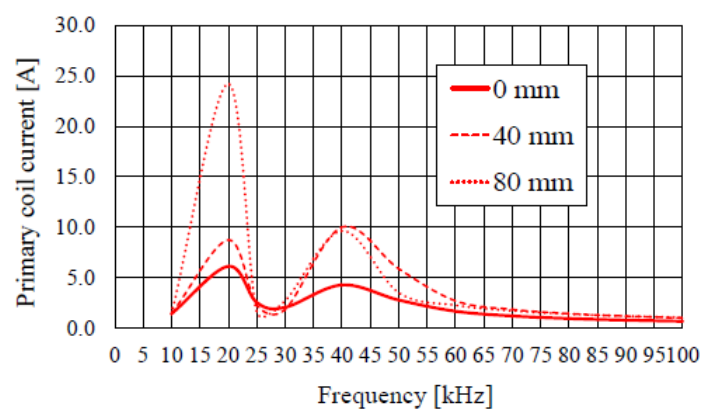

Figure 12: Primary coil current as a function of frequency of $\mathrm{WPT}_{\mathrm{RC}}$ for different misalignments.

teristics of $\mathrm{WPT}_{\mathrm{RC}}$ resembles those of $\mathrm{WPT}_{\mathrm{SP}}$ with the increase in $C_{2}$. On the other side, the advantage of such flat characteristics of the output voltage for the misalignment in $\mathrm{WPT}_{\mathrm{RC}}$ is lost with adding $C_{2}$. In addition, the burden of the $C_{1}, C_{r}$, and $C_{2}$, such as current and voltage characteristics must be considered for the misalignment.

Next, an attempt is made to investigate a compensation method for the misalignment by controlling the magnitude of the input voltage $V_{\text {in }}$ and the frequency $\mathrm{f}$ of $V_{\text {in }}$. As shown in Fig. 9, the impedance from the primary side is dominated by a resistance and inductive load for a coil misalignment.

If the frequency of $V_{\text {in }}$ decreases, then the impedance will change only by the resistance component so that the power factor of the circuit will be controlled at 1.0. On the other hand, the control increases a burden of resonance capacitors $C_{1}$ and $C_{r}$. In particular, the current and voltage of $C_{1}$ increase more drastically than those of $C_{r}$. It is because the impedance viewed from the primary side is reduced to a small value by controlling the frequency.

Fig. 12 and 13 show frequency dependence of primary coil current and impedance locus for misalignment with the frequency changed of $\mathrm{WPT}_{\mathrm{RC}}$, respectively. As a result, it can be mentioned that the impedance viewed from the primary coil side changes only with the resistance by controlling the frequency of $V_{i n}$. In addition, it is confirmed that the primary current increases with decreasing the frequency.

Fig. 14 shows input and output voltages for misalignment of $\mathrm{WPT}_{\mathrm{RC}}$ with and without the controlling $\mathrm{f}$ and $V_{i n}$. Note

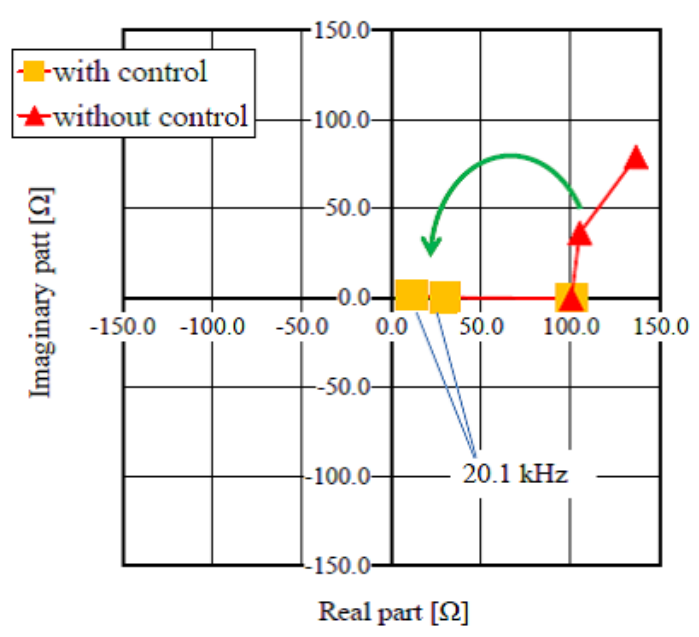

Figure 13: Impedance locus for misalignment of $\mathrm{WPT}_{\mathrm{RC}}$ with the input voltage and frequency adjusted.

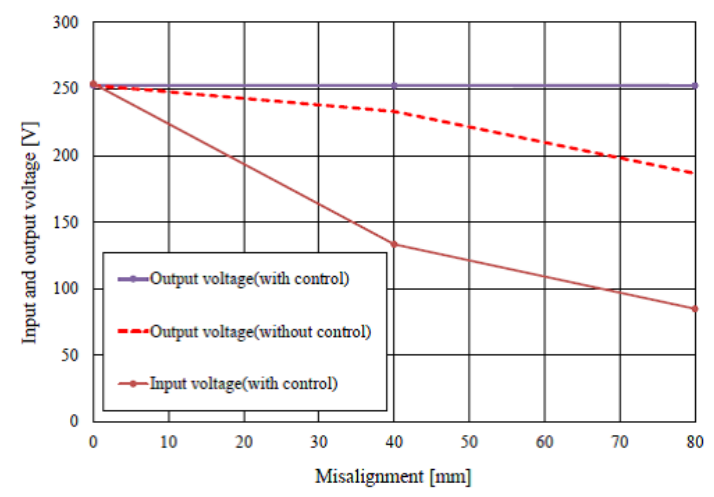

Figure 14: Input and output voltage as a function of misalignment of $\mathrm{WPT}_{\mathrm{RC}}$ with $V_{i n}$ and frequency controlled.

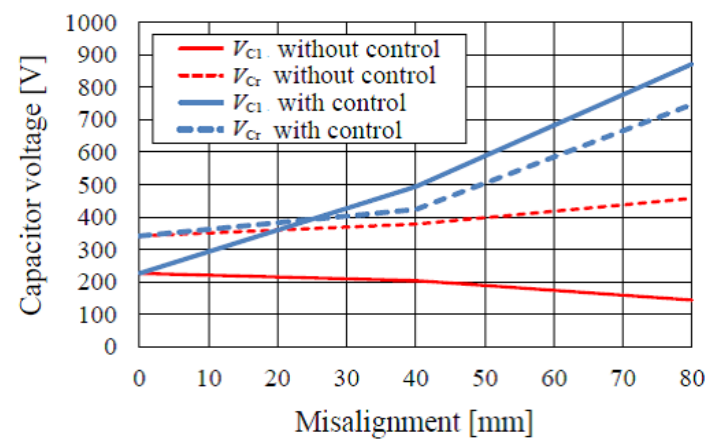

Figure 15: Resonance capacitor voltage as a function of misalignment of $\mathrm{WPT}_{\mathrm{RC}}$ with $V_{\text {in }}$ and frequency controlled.

that $V_{\text {in }}$ was controlled to keep the output power as a constant. Two parameters i.e. magnitude of $V_{\text {in }}$ and $\mathrm{f}$ can control the output power Pout as a constant.

Fig. 15 shows the misalignment dependence of the resonance capacitor voltage of $\mathrm{WPT}_{\mathrm{RC}}$ with the frequency and magnitude of $V_{\text {in }}$ changed. As can be seen, results, the voltage, and current of $C_{1}$ exceeded those of $C_{r}$, for instance, the voltage of $C_{1}$ at $80 \mathrm{~mm}$ of misalignment is four times of $0 \mathrm{~mm}$ of misalignment.

Fig. 16 shows misalignment dependence of the magnetic 


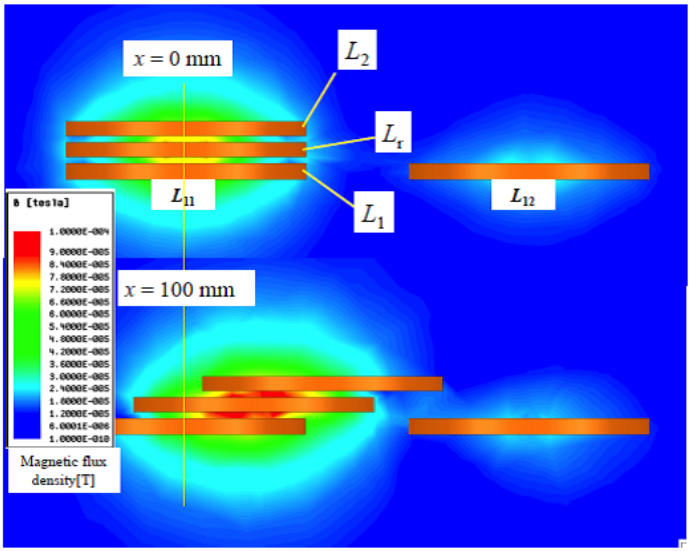

Figure 16: Magnetic flux density as a function of misalignment of $\mathrm{WPT}_{\mathrm{RC}}$ without $V_{\text {in }}$ and frequency controlled (without ferrite core).

flux density distribution of $\mathrm{WPT}_{\mathrm{RC}}$ when two primary coils are connected in series and set with gap lengthen $G$ of 20 $\mathrm{mm}$. Primary coils were set $250 \mathrm{~mm}$ interval. As can be seen results, Maximum flux density point was the shift to right side direction which is movement direction of the secondary coil with increasing the misalignment.

Finally, the advantages of $\mathrm{WPT}_{\mathrm{RC}}$ will be described by reflecting simulation results. Controlling the position of the repeating coil can keep the output voltage as almost constant. Even if a relatively large misalignment occurs, the output voltages decrease in a safe direction for the load. In addition, the burden of the resonance capacitor for repeating coil is always maximized, so the system design of $\mathrm{WPT}_{\mathrm{RC}}$ considering the misalignment should take it account to resonance capacitor of repeating coil.

In particular, $\mathrm{WPT}_{\mathrm{RC}}$ has with the power transmitting efficiency kept high even for the large misalignment and decreased output power. In other words, even if the power factor 1 control is not performed, $\mathrm{WPT}_{\mathrm{RC}}$ has no problem if allowable position range that has high power transmitting efficiency is considered.

\section{Conclusion}

This paper compares the electrical characteristics of S-P (Series - Parallel) type with those of a repeating coil type wireless power transfer (WPT) system. The features of the two types of WPT systems are described for the same output power using a same coil model. In general, the misalignment of power transmitting and receiving coils causes an output power to decrease using resonance capacitors with large operations current and voltage. From the viewpoint, a compensation method for the misalignment is investigated to reduce this burden of the resonance capacitor.

Simulation is made on electrical characteristics such as output power and power transfer efficiency of a proposed WPT system applied to the automatic guided vehicle (AGV) based on an equipment circuit combining results of the electromagnetic analysis. As a result, it is found that a repeating coil keeping the center position between the primary and secondary coils can suppress the burden of the resonance capacitor so as to improve the transmission power of WPT system.

In particular, $\mathrm{WPT}_{\mathrm{RC}}$ has with the power transmitting efficiency kept high even for the large misalignment and decreased output power. In other words, even if the power factor 1 control is not performed, $\mathrm{WPT}_{\mathrm{RC}}$ has no problem if allowable position range that has high power transmitting efficiency is considered.

\section{Acknowledgment}

This work was supported by JSPS KAKENHI Grant Number $15 \mathrm{~K} 18022$. The authors would like to acknowledge the concerned members.

\section{References}

[1] T. Kudo, T. Toi, Y. Kaneko, S. Abe, "Contactless Power Transfer System Suitable for low Voltage and Large Current Charging for EDLCs", Power Electronics Conference (IPEC-Hiroshima 2014 - ECCE-ASIA), pp.1109-1114, (2014).

[2] X. Qu, H. Han, S. Wong, C. Tse, W. Chen, "Hybrid IPT Topologies With Constant Current or Constant Voltage Output for Battery Charging Applications", IEEE Transactions on Power Electronics, pp.6329-6337, (2015).

[3] K. Inoue, K. Kusaka, J. Itoh, "Development of Inductive Power Transfer System for Excavator Considered Load Disturbance", 2017 IEE-Japan Industry Applications Society Conference, pp.I-435-I-438, (2017). (in Japanese)

[4] T. Imura, Y. Hori, "Unified Theory of Electromagnetic Induction and Magnetic Resonant Coupling”, IEEJ Transactions on Industry Applications, Vol.135, No.6, pp.697-710, (2015). (in Japanese)

[5] Hongtai Cheng, Lina Hao, Zhong Luo, and Fei Wang, "Establishing the Connection between Control Theory Education and Application: An Arduino Based Rapid Control Prototyping Approach", International Journal of Learning and Teaching, vol.2, no.1, pp.67-72, June, 2016.

[6] S. Kitazawa, K. Kondo, T. Kashiwagi, "An Evaluation of Power Flow Control of the Power Conversion Circuit for Contactless Power Transformer Systems at the Coil Misalignment", IEEJ Transactions on Industry Applications, Vol.133, No.5, pp.518-525, (2013). (in Japanese)

[7] A. Zaheer, G. Covic, D. Kacprzak, "A Bipolar Pad in a 10-kHz 300-W Distributed IPT System for AGV Applications", IEEE Transactions on Industrial Electronics, Vol.61, pp.3288-3301, (2014).

[8] T. Higashino, Z. Ma, M. Okada, Y. Tatsuta, Y. Goto, Y. Tsuruda, R. Tanaka, "Proposal of Wireless Power Transfer using Parallel Line Feeder", TECHNICAL REPORT OF IEICE., pp.20-25, (2013). (in Japanese)

[9] H. Abe, T. Akiyama, M. Ozaki, H. Kohara, "Simple Equivalent Circuit for a Wireless Power Transfer System Using a Repeating Coil and Effects Confirming the Simplification 
in the Output Voltage Estimation”, IEEJ Transactions on Industry Applications, Vol.135, No.6, pp.679-688, (2015). (in Japanese)

[10] M. Kato, T. Imura, Y. Hori, "Study about Relation of Efficiency between Receiving Antenna Position and Efficiency for Wireless Power Transfer for Moving Vehicle with Relay Antenna", 2012 IEE-Japan Industry Applications Society Conference, pp.219-222, (2012). (in Japanese)

[11] A. Imakiire, M. Hikita, K. Yamamoto, "Proposal of PM motor driving system consist of PWM inverter with voltage booster for applying to automated guided vehicle", International Conference on Electrical Machines and Systems (ICEMS), pp.2052-2057, (2015).

[12] H. Tokunaga, A. Imakiire, M. Kozako, M. Hikita, "Clarification of Resonance Method for Wireless Power Transfer System Using Repeating Coil”, 2017 IEE-Japan Industry Applications Society Conference, pp.453-454, (2017).

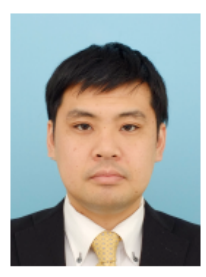

Akihiro Imakiire (Member) was born in Japan in 1985. He received the B.E. and M.E. degrees from Kagoshima University, Kagoshima, Japan in 2007 and 2009, respectively. He was work with Fuji Electric Co., Ltd., Tokyo Japan from 2009 to 2012 . He has been with the Department of Electrical and Electronic Engineering, Kyushu Institute of Technology since 2013, where he is currently an Assistant Professor. His research interests are ac motor drives, power converter circuits and wireless power transfer. Dr. Imakiire is a member of the Institute of Electrical Engineers of Japan (IEEJ) and the Institute of Industrial Applications Engineers (IIAE).

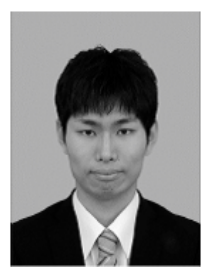

Hideaki Tokunaga (Non-member) was born in Japan in 1993. He received the B.E. and M.E. degrees from Kyushu Institute of Technology, Fukuoka, Japan in 2016 and 2018, respectively. His research interests are wireless power transfer and power converter circuits.

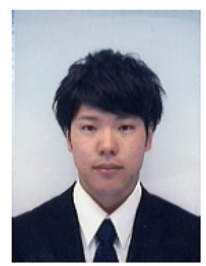

Akihiro Kawagoe (Non-member) was born in Japan in 1995. He received the B.E. degrees from Kyushu Institute of Technology, Fukuoka, Japan in 2016. His research interests are wireless power transfer and power converter circuits.

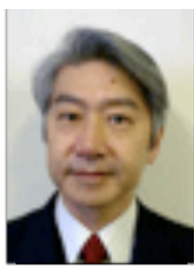

Masayuki Hikita (Non-member) was born in Japan in 1953. He received the B.S., M.S. and Dr. degrees in electrical engineering from Nagoya University, Japan, in 1977, 1979 and 1982, respectively. He was assistant Professor, Lecture, and Associate Professor at Nagoya University in 1982, 1989 and 1992, respectively. Since 1996, he has Scientist at the High Voltage Laboratory in MIT, USA, from 1985 to 1987 . He has been interested in the development of diagnostic technique of electric power apparatus and insulation system of power electronics device and apparatus. Dr. Hikita is a member of the Japan Society of Applied Physics and the Institute of Electrical Engineers of Japan (IEEJ). 